University of Nebraska - Lincoln

DigitalCommons@University of Nebraska - Lincoln

1988

\title{
Spermiogenesis of Heliothis virescens (Lepidoptera: Noctuidae): An Ultrastructure Study of Eupyrene Sperm in Sterile Backcross Males
}

Leo E. LaChance USDA-ARS, Metabolism and Radiation Research Laboratory, State University Station, Fargo, North Dakota 58105

Geneva Olstad USDA-ARS, Metabolism and Radiation Research Laboratory, State University Station, Fargo, North Dakota 58105

Follow this and additional works at: https://digitalcommons.unl.edu/entomologyother

Part of the Entomology Commons

LaChance, Leo E. and Olstad, Geneva, "Spermiogenesis of Heliothis virescens (Lepidoptera: Noctuidae): An Ultrastructure Study of Eupyrene Sperm in Sterile Backcross Males" (1988). Entomology Papers from Other Sources. 98.

https://digitalcommons.unl.edu/entomologyother/98

This Article is brought to you for free and open access by the Entomology Collections, Miscellaneous at DigitalCommons@University of Nebraska - Lincoln. It has been accepted for inclusion in Entomology Papers from Other Sources by an authorized administrator of DigitalCommons@University of Nebraska - Lincoln. 


\title{
Spermiogenesis of Heliothis virescens (Lepidoptera: Noctuidae): An Ultrastructure Study of Eupyrene Sperm in Sterile Backcross Males
}

\author{
LEO E. LACHANCE AND GENEVA OLSTAD
}

USDA-ARS, Metabolism and Radiation Research Laboratory, State University Station, Fargo, North Dakota 58105

Ann. Entomol. Soc. Am. 81(2): 301-307 (1988)

ABSTRACT Sterile backcross (BC) males originate from the hybridization of Heliothis subflexa (Guennée) females to $H$. virescens (F.) males followed by recurrent backcrossing of the fertile female progeny to $H$. virescens males. Ultrastructural transmission electron microscope (TEM) studies of the postmeiotic maturation of eupyrene sperm cells in BC males, and comparisons with the cells in normal $H$. virescens males, show that the early stages in cell differentiation and maturation are similar in $\mathrm{BC}$ and normal $\boldsymbol{H}$. virescens males. In 3- or 5-d-old pupae, some of the BC spermatids contain large vacuoles in the cytoplasm or in the mitochondrial derivatives (MDs). Also, the MDs are greatly enlarged at certain levels in the sperm tail and appear normal in other sections. Other structures in the maturing sperm cell, such as the axial filament, cell membranes, manchette system, satellite bodies, and cristae, maintain normal morphology. In more mature eupyrene sperm bundles, it appears that cell membranes often rupture and some of the cells fuse to form abnormal structures with multiple axial filaments and malformed MDs. In any given section we commonly observe some cells with gross abnormalities of the MDs and neighboring cells in the section that are normal. As maturation of the eupyrene sperm bundle continues, the abnormalities become much more severe. In adult BC males, some cells appear normal in some sections. However, in other sections it is difficult to recognize any normal eupyrene sperm cells, and there is generalized breakdown of many cells in the sperm bundle.

KEY WORDS Insecta, membranes, axial filament, mitochondrial derivative

THE ULTRASTRUCTURAL details of postmeiotic eupyrene sperm maturation in normal male Heliothis virescens $(\mathrm{F}$.) were presented in an earlier paper (LaChance \& Olstad in press). Our primary interest in that study was to gather sufficient information to permit comparison with the same process in sterile backcross (BC) Heliothis males.

Sterile BC males originate from a cross involving Heliothis subflexa (Guennée) females and H. virescens males. Progeny of this interspecific cross consist of fertile females and sterile males (Laster 1972). The $F_{1}$ hybrid females are then backcrossed to $H$. virescens males and again produce fertile females and sterile males. Thus, by recurrent backcrossing of the $\mathrm{BC}$ females to $H$. virescens males, it has been possible to maintain one line for over 158 generations $\left(\mathrm{BC}_{158}\right)$ that consists of fertile females and sterile males. The potential use of $\mathrm{BC}$ sterility to suppress populations of $H$. virescens has been evaluated (Parvin et al. 1976, Makela \& Huettel 1979, Proshold et al. 1983a,b, Proshold 1984). These studies showed that BC sterility has considerable promise for population suppression.

The cellular basis for male sterility has also been examined (Proshold \& LaChance 1974, Proshold et al. 1975, Richard et al. 1975, Goodpasture et al. 1980a,b, LaChance \& Karpenko 1981, 1983, LaChance 1984, Miller \& Huettel 1986, Miller et al. 1986). Lepidopteran males produce apyrene and eupyrene sperm, both of which are transferred to the female during mating. The eupyrene sperm are necessary for egg fertilization and, thus, for fertility. The apyrene sperm are anucleate and do not fertilize eggs but accompany the eupyrene sperm into the spermatophore and into the spermathecae of the female. The sterile BC males produce normal-appearing apyrene sperm in normal quantities, and these are commonly found in the spermathecae of females mated to BC males (LaChance \& Karpenko 1981, 1983). The sterile $\mathrm{BC}$ males produce eupyrene sperm bundles in the testis (LaChance 1984), but very few bundles reach the duplex region of the male reproductive tract. Thus, they are not available for incorporation into a spermatophore and for transfer to females during mating. The few eupyrene sperm bundles that descend to the duplex region of the reproductive tract have distinctly swollen areas distributed along the sperm tail (LaChance 1984). However, little is known about the nature of the abnormalities in eupyrene sperm bundles located in the testis (see Miller \& Huettel 1986), about the point during maturation that eupyrene sperm development begins to be abnormal, or about specifically which structures are involved. This information would contribute to our knowledge of the basis of $\mathrm{BC}$ male sterility.

\section{Materials and Methods}

Insects used in these studies came from two different BC lines maintained in our laboratory. The diet and rearing conditions were the same as used 
for normal Heliothis colonies (LaChance \& Olstad in press). Males from two BC lines were selected over several generations (BC 61, 85, 113, etc., generations). The single fused testis was dissected in saline from prepupae, 1-, 3-, 5-, 7-, and 9-d-old pupae, and newly emerged adult males and processed for transmission electron microscopy (TEM) as described previously (LaChance \& Olstad in press).

\section{Results}

The prepupal testis contains mostly very early spermatids and some elongating cysts, and the adult male testis contains mostly large numbers of eupyrene and apyrene sperm bundles (LaChance \& Olstad in press). However, there is no direct correlation of eupyrene sperm maturation stage with age. Although we refer to the developmental stage in the text and figure legends, we do not imply that a particular cell type or abnormality is found only in that developmental stage (i.e., 7-d-old pupae or adult). However, certain abnormalities are observed at certain eupyrene maturation stages.

In $\mathrm{BC}$ males, eupyrene sperm development appears normal during the early postmeiotic maturation stages. In prepupae and 1-d-old pupae, the young spermatid cysts of 256 cells (Loeb \& Brinbaum 1981) appear normal. The cell has a nucleus surrounded by a double membrane with numerous nuclear pores, and an acrosome derivative. The cytoplasm contains numerous mitochondria, Golgi complexes, and rough endoplasmic reticulum (ER) (Fig. 1). The processes observed in normal males, such as fusion of numerous mitochondria into a single nebenkern, division of the nebenkern into two mitochondrial derivatives (MDs), elongation of the MDs as the sperm tail elongates, formation of the axial filament or axoneme, and many other features described in early maturation (LaChance \& Olstad in press), appear normal. At this early stage, cells with two axial filaments occur at a very low frequency similar to that in normal Heliothis males.

Examination of cross sections through eupyrene sperm bundles in 1-d-old pupae reveals the same type of maturing sperm cells present in normal Heliothis males. There is a mixture of maturation stages (see Table 1, LaChance \& Olstad in press). Most cells have two MDs, an axial filament, multivesicular bodies, a nucleus, an acrosome derivative, and considerable ER and cytoplasm (Fig. 2).

Sections from 3- and 5-d-old pupae contain a mixture of normal and abnormal cells. Virtually all sections have normal appearing spermatids with the two MDs, axial filament, and cytoplasm containing multivesicular bodies (Fig. 3-6). However, many sections contain cells with large vacuoles in the MDs and cytoplasm (Fig. 3-5). This finding is the first clear indication of abnormal cell development in eupyrene spermatids of BC males. In some cells the vacuoles are considerably larger than the rest of the cell (Fig. 3-5).
As eupyrene cell maturation continues in older pupae, numerous abnormalities in eupyrene sperm development are observed. The most general feature is that virtually any section through the tail portion of sperm cells present in a bundle contains a few abnormal cells, and the rest appear normal (Fig. 4-6). Sections through the nuclear end of the sperm bundle appear normal. Sections through the tail portion of the eupyrene spermatid contain the most abnormalities, which involve primarily the development of the MDs. Most obvious is the swelling, enlargement, or blebbing of these structures, while other structures within the cell retain their normal morphology, and neighboring sperm cells may appear completely normal (Fig. 9-11). Serial sections along the same bundle will generally reveal that sperm tails appearing completely normal at one level are abnormal in another area. Enlargements in the tail portion of the sperm cell do not always involve the MDs. Quite often the MDs and axial filament have a normal size and the cytoplasm is swollen (Fig. 13).

Examination of hundreds of micrographs from BC males indicates that, very likely, each sperm tail within a bundle contains, in the early stages, one or more grossly swollen areas. Whether or not these blebs are distributed randomly within the tail region is not known, although this appears to be the case.

Other structures in the eupyrene cells develop normally (Fig. 5-7). Microtubules of the manchette develop around the MDs, cristae form on the inner membrane of the MDs, the satellite body develops normally, and septa linking the satellite body to the inner membrane of the cell are visible. The axial filament appears normal.

In still more advanced stages of maturation, many cells show an abundance of rough ER (Fig. 13 and 16), which could indicate a high level of metabolic activity or that developmental events in the sperm cell are out of synchrony. An increased number of cells have two or more axial filaments (Fig. 7, 8, and 12) and very often this difference is accompanied by the development of two or more satellite bodies (Fig. 12, 15, and 17).

The eupyrene sperm bundles in 7-and 9-d-old pupae continue to exhibit a mixture of normal and abnormal development depending on which part of the sperm tail is present in a particular section. In older pupae and adult males, the eupyrene cells are greatly disrupted, and often it is difficult to recognize various structures of the cells. In normal males, sperm cells in the bundles present are highly ordered with clearly developed radial mantles (see Fig. 18-20 in LaChance \& Olstad in press). In BC males, we have consistently observed many sperm bundles with $<256$ sperm and a disorganized arrangement of abnormal cells (Fig. 12-17).

In older pupae and adult BC males, some eupyrene spermatids exhibit completely normal sections in the tail region (Fig. 18), and other cells show a complex mixture of totally abnormal struc- 

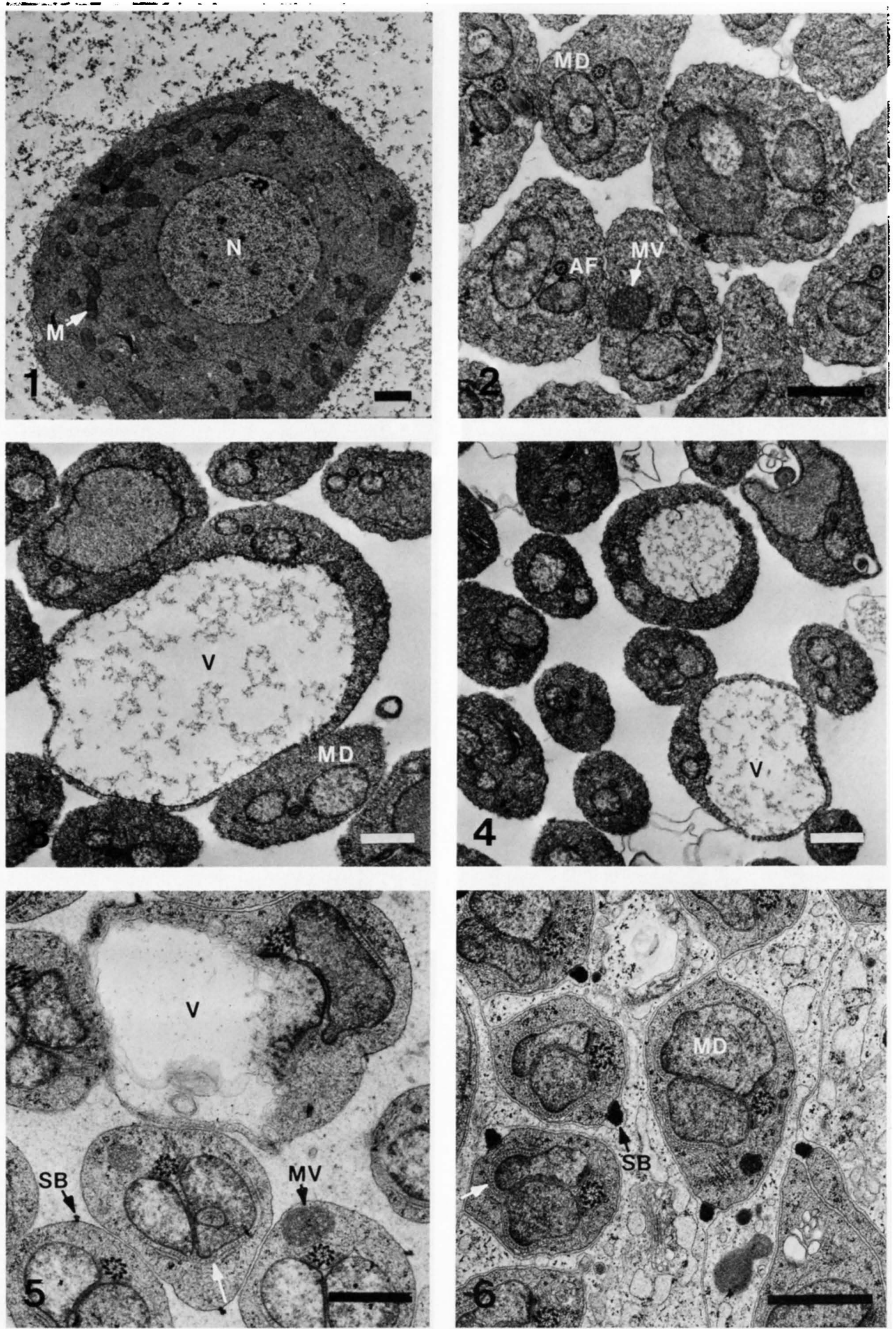

Fig. 1-6. Cross section through eupyrene sperm cells in various stages of maturation from sterile $\mathrm{BC}$ male testes. Bar in all figures $=1 \mu \mathrm{m}$. (1 and 2) From 1-d-old pupae. (1) Section through nuclear portion of a very young spermatid prior to formation of the nebenkern, nucleus $(\mathrm{N})$, and mitochondria $(\mathrm{M})$. (2) Older spermatid stage. Cells have two MDs, one axial filament (AF), and multivesicular bodies (MV). (3 and 4) From 3-d-old pupae. Both figures show cross sections through normal eupyrene cells and cells with large vacuoles (V) and MDs in cytoplasm. (5 and 6) From 5-d-old pupae, a more advanced spermatid stage than previous figure. (5) Satellite body (SB) beginning to form. Note normal cell and one with large V. (6) Well-developed SB and MD. Note two normal eupyrene cells at left; cell in center appears enlarged, arrows in 5 and 6 point to manchette tubes (MA) around MDs. 

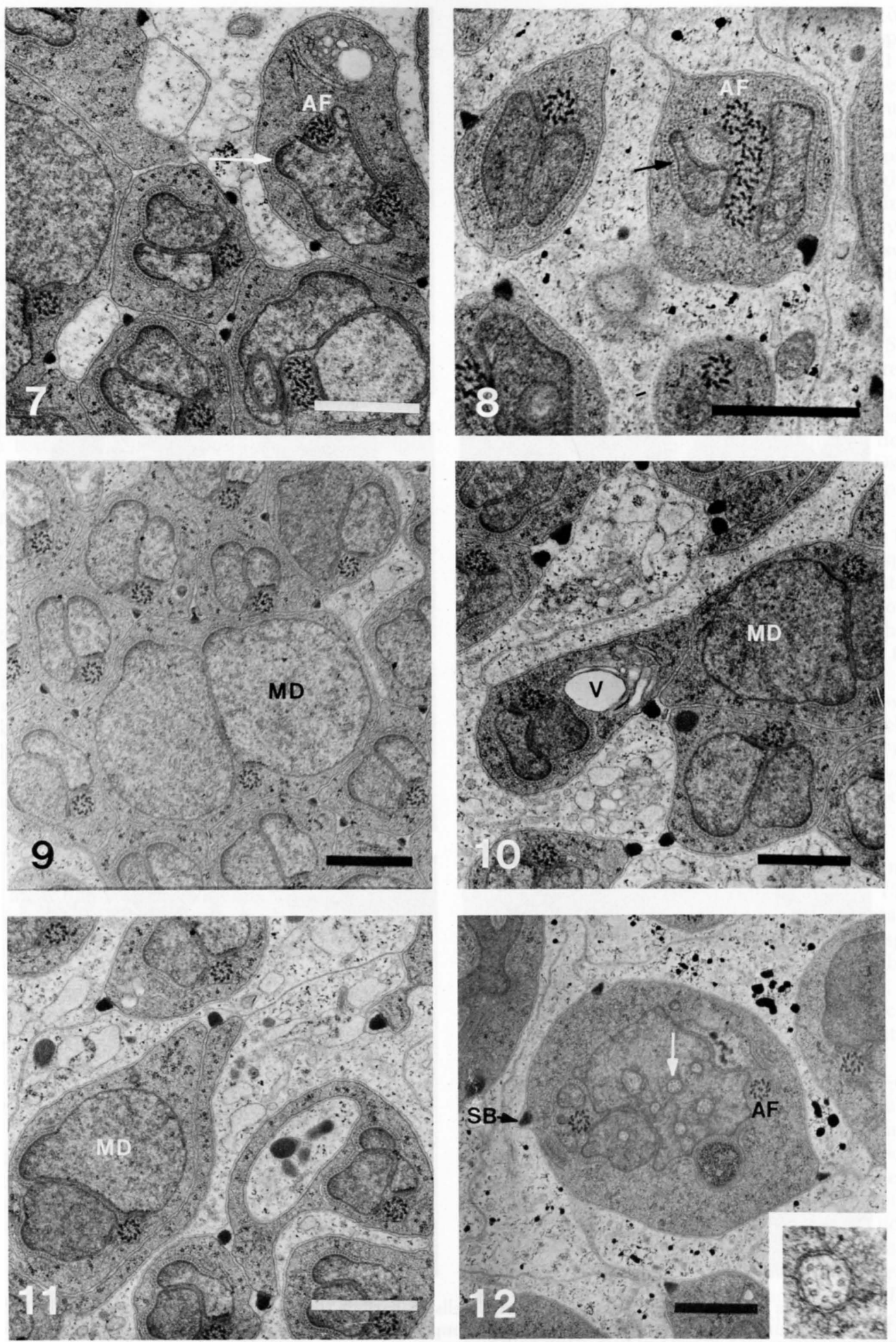

Fig. 7-12. Cross sections through eupyrene sperm cells in various stages of maturation from sterile BC male testes. Bar in all figures $=1 \mu \mathrm{m}$. (7) From 5-d-old pupae. Two cells at right have two axial filaments (AF) and abnormal MDs. White arrow points to manchette tubules (MA). (8) From 9-d-old pupae. Cell with four AFs at right; normal cell, top left. Black arrow points to MAs. (9 and 10) Eupyrene spermatids from 5-d-old pupae. Each figure has sections from normal cells and cells with enlarged MDs. Cell in 10 has a V. (11) From 5-d-old pupae. Abnormal cells with two AFs; three satellite bodies (SB); and abnormal, misshapen MDs surrounding tubular structures (white arrow). Inset shows tubular structure enlarged to $55,836 \times$. 

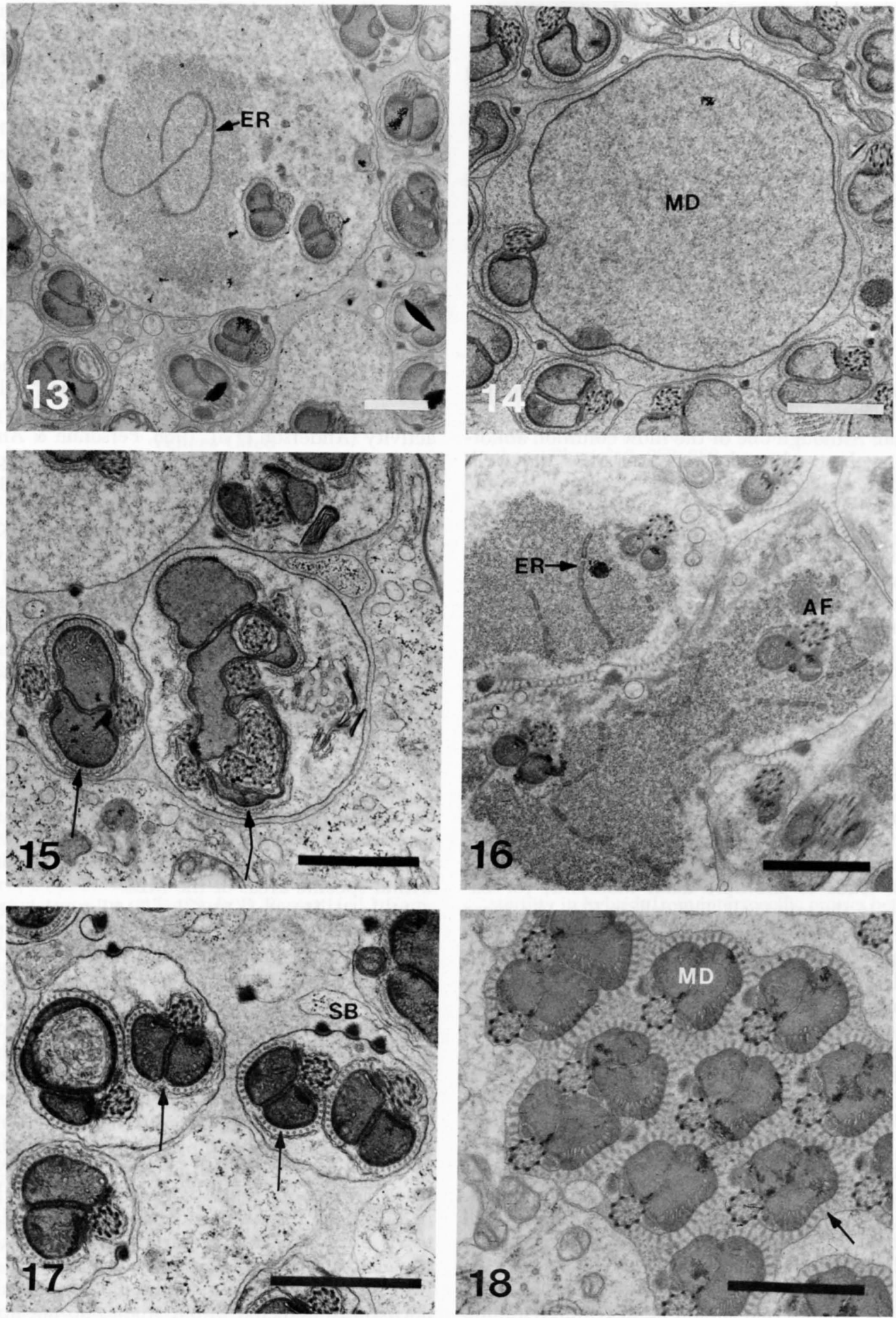

Fig. 13-18. Cross sections through eupyrene sperm cells in various stages of maturation from sterile $\mathrm{BC}$ male testes. Bar in all figures $=1 \mu \mathrm{m}$. (13) Enlarged cell contains two normal-sized tail cross sections and an inclusion of rough ER. (14) Section through cell with one normal and one enlarged MD. Compare with normal cells in figure. (15) Abnormal cells with two and eight axial filaments (AF). Black arrow points to manchette tubules (MA). (16) Cells with two sets of MDs and AFs within same cell membrane. Cells have strands of rough ER. (17) Two cells with two tail structures. One cell with three SBs. Black arrows point to MAs. (18) Normal cells in BC male. Note radial mantle. Black arrow surrounding MDs. 
tures (Fig. 10-17). Cells with multiple axial filaments are common (Fig. 8, 12, and 15). Also some spermatids appear to have normal MDs and axial filaments, but grossly swollen areas surround the normal-appearing structures (Fig. 13).

\section{Discussion}

From our observations it appears that in BC males, the spermatids undergo the early stages of spermiogenesis normally. The axial filament forms, the numerous mitochondria fuse to form the nebenkern, and this structure divides into two MDs. Concurrently, the round cell begins to elongate. After the two MDs have formed, vacuoles begin to appear in the cytoplasm, the MDs, or both. The vacuoles swell and cause localized blebs or enlargements along the sperm tail. In any section, only a few cells are affected and the remainder appear normal. Although one of the most common abnormalities observed is enlargement of MDs, the swellings do not always involve these structures. In some cells the axial filament and MDs are normal, and the cytoplasmic regions of the cell are swollen (Fig. 3 and 5). As spermiogenesis proceeds, there is an increased incidence of abnormalities in sperm cells, and in some bundles it appears that only masses of axial filaments remain and the other structures have disappeared.

There is a high frequency of cells with multiple axial filaments (ranging from 2 to 10 ), two or more sets of MDs, and other multiple structures. Also, we observed a decrease in the number of eupyrene cells in a sperm bundle. Some sperm bundles contain only $30-80$ cells, compared to 256 cells in eupyrene bundles of normal males. These abnormalities could be due to two factors.

Spermatid cells may fuse during maturation, which leads to multiple axial filaments, for example, in the same cell. The cells in Fig. 16 appear to be fusing or have already fused and contain structures from two or more cells. Other examples are depicted in Fig. 12, 13, 15, 16, and 17. The cell in Fig. 12 has an abnormal structure with microtubules inside a mitochondrial derivative. These microtubules normally occur around the MDs, not inside them. Because the microtubules (Fig. 12) are the same size as those found in the manchette of normal males, it is possible that during cell fusion, the manchette tubules surrounding the MDs can become incorporated within them. Alternatively, the observation of multiple axial filaments, MDs, and other structures in the same sperm cell could be due to spermatocytes or spermatogonia that fail to undergo cytokenesis, which leads to the retention, within an undivided cytoplasmic mass, of the organelles that should be distributed among the daughter cells if cytokenesis had occurred.

A major problem in relating the present ultrastructural findings to specific biochemical events in the sperm cell is our ignorance of the biochemical function of organelles in the sperm cell. Structure of organelles in the sperm cell has been described in several insects, but organelle function is not well understood. The MDs are a good example. In most insect sperm, these large structures extend from the nuclear to near the caudal end of the sperm cell. They are complex, highly differentiated structures, yet little is known about how and where biochemical functions are partitioned in these structures. Abnormalities observed in BC males occur at certain places in the tail region, and other regions appear normal. The location of abnormal swollen areas in the sperm tail could be either random or highly specific. We do not know if the large MDs have specific areas along their length where certain metabolic reactions take place.

In other organisms, there is evidence of localized activity in certain portions of the MDs. Kreb cycle enzymes were reported confined to the secondary helices where the major helix contained a large quantity of glycogen together with phosphorylase activity (Anderson et al. 1968, Personne \& Anderson 1969, Favard \& André 1970). In gastropods, Anderson \& Personne (1970) reported that "these mitochondria exhibit therefore the complete spatial segregation of systems of enzymes of the Krebs cycle and respiratory pathways." We are not aware of similar studies in insects that have localized specific functions to certain regions of the MDs, although respiratory enzymes are present in the MDs and axial filaments of insects. In their studies on Bacillus rossius (a phasmid) and Ceratitis capitata, Bigliardi et al. (1970) found that only UTPase and, in Ceratitis, cytochrome oxidase were abundant in the mitochondria while other enzymes were almost exclusively localized in the axial filament complex. The outer tubules of the axoneme of sperm insects contain an active polysaccharide with properties similar to glycogen (Baccetti et al. 1969a,b). However, these studies do not deal with localizations within specific areas of the MDs.

Miller \& Huettel (1986) and Miller et al. (1986) have formulated a working hypothesis that accounts for male sterility in BC males, namely, "that a mitochondrial function peculiar to sperm cells is impaired in backcross moths due to the inability of evolutionarily divergent nuclearly encoded $(H$. virescens) and mitochondrially encoded ( $H$. subflexa) RNA or protein molecules to interact appropriately." Miller et al. (1986) found that steadystate levels of mitochondrial transcripts from BC testes were reduced approximately 3 times relative to $H$. virescens, and that at least three mitochondrial RNAs were found not to be polyadenylated in $\mathrm{BC}$ testes and also reduced in amount relative to $H$. virescens. It is important to note that biochemical differences were detectable in fourth- and fifth-stage larvae, whereas the ultrastructural abnormalities detected in our studies do not appear until much later stages.

From our present results and those reported earlier (LaChance 1984) it appears that the major dysfunction in sperm of BC males is the localized enlargement of MDs or cytoplasm at various locations in the sperm tail. These swellings may be specific to areas of the MDs where specific func- 
tions occur. Swellings may represent an accumulation of a substrate or an intermediate metabolite that is not being processed because a specific pathway is blocked. The blocked function may relate to certain $H$. virescens gene products required for normal spermiogenesis that cannot function in $H$. subflexa cytoplasm. Cytochemical studies on the MDs of $\mathrm{BC}$ males would indicate more about the nature of the major dysfunction in male $\mathrm{BC}$ sterility.

\section{Acknowledgment}

We thank John Riemann and George Gassner for their help in interpreting certain ultrastructural features and S. Newman, R. Roehrdanz, J. Seawright, M. Huettel, and S. Miller for reading early drafts of this manuscript.

\section{References Cited}

Anderson, W. A. \& P. Personne. 1970. Recent cytochemical studies on spermatozoa of some invertebrate and vertebrate species, pp. 431-450. In B. Baccetti [ed.], Comparative spermatology. Academic, New York.

Anderson, W. A., P. Personne \& J. André. 1968 Chemical compartmentalization in Helix spermatozoa. J. Microscopie 7: 367-390.

Baccetti, B., E. Bigliardi, R. Dallai \& F. Rosati. 1969a The outer course fibers of the axial filament complex of insect spermatozoa. J. Microscopie 8: 32a.

Baccetti, B., R. Dallai \& F. Rosati. 1969b. The spermatozoon of Arthropoda. III. The lowest holometabolic insects. J. Microscopie 8: 233-248.

Bigliardi, E., B. Baccetti, G. Burrini \& V. Pallini. 1970. The spermatozoon of Arthropoda. XII. The distribution of some enzymes in the insect sperm tail, pp. 451-464. In B. Baccetti [ed.], Comparative spermatology. Academic, New York.

Favard, P. \& J. André. 1970. The mitochondria of spermatozoa, pp. 415-429. In B. Baccetti [ed.], Comparative spermatology. Academic, New York.

Goodpasture, C., L. E. LaChance \& R. D. Richard. 1980a. Persistence of abnormal spermiogenesis in the backcross generations of interspecific hybrids between Heliothis virescens $\times H$. subflexa. Ann. Entomol. Soc. Am. 73: 397-403.

Goodpasture, C., R. D. Richard, D. F. Martin \& M. L. Laster. 1980b. Sperm cell abnormalities in progeny from interspecific crosses between Heliothis virescens and $H$. subflexa. Ann. Entomol. Soc. Am. 73 : 529-532.

LaChance, L. E. 1984. Hybrid sterility: eupyrene sperm production and abnormalities in the backcross generations of interspecific hybrids between Heliothis subflexa and $H$. virescens (Lepidoptera: Noctuidae). Ann. Entomol. Soc. Am. 77: 93-101.

LaChance, L. E. \& C. P. Karpenko. 1981. Effect of seven antibiotics on the growth and reproduction of Heliothis subflexa $\times H$. virescens interspecific hybrids and backcross males. Ann. Entomol. Soc. Am. 74: 493-497.

1983. Hybrid sterility in Heliothis subflexa $\times \mathrm{H}$. virescens (Lepidoptera: Noctuidae) crosses: expression after injection with antiviral agents, heat shocks, and rearing at extreme temperatures. Ann. Entomol. Soc. Am. 76: 104-109.

LaChance, L. E. \& G. Olstad. In press. Ultrastructural study of spermiogenesis in Heliothis virescens (Lepidoptera: Noctuidae). I. The development of eupyrene sperm in prepupae, pupae and adults. Ann Entomol. Soc. Am.

Laster, M. L. 1972. Interspecific hybridization of $\mathrm{He}$ liothis virescens $\times$ H. subflexa. Environ. Entomol. 1: 682-687.

Loeb, M. J. \& M. J. Birnbaum. 1981. The relationship of hemolymph osmotic pressure to spermatogenesis in the tobacco budworm, Heliothis virescens. Int. J. Invert. Reproduction 4: 67-79.

Makela, M. E. \& M. D. Huettel. 1979. Model for genetic control of Heliothis virescens. Theor. Appl. Genet. 54: 225-233.

Miller, S. G. \& M. D. Huettel. 1986. Mitochondrial biogenesis in Heliothis virescens, H. subflexa, and their male sterile backcross hybrids. Arch. Ins. Biochem. Physiol. 3: 363-380.

Miller, S. G., M. D. Huettel, M. B. Davis, E. H. Weber \& L. A. Weber. 1986. Male sterility in Heliothis virescens $\times H$. subflexa backcross hybrids. Evidence for abnormal mitochondrial transcripts in testes. Mol. Genetics 203: 451-461.

Parvin, D. W., Jr., M. L. Laster \& D. F. Martin. 1976. A computer program for simulating the theoretical suppression of the tobacco budworm by genetic sterilization. Mississippi Agricultural and Forest Experiment Station, Dep. Agric. Econ. Staff Papers Series.

Personne, P. \& W. A. Anderson. 1969. Compartimentage des activités enzymatiques dans le spermatozoide de certains mollusques. I. Localization des déhydrogenases. J. Cell Sci. 4: 693-707.

Proshold, F. I. 1984. Release of backeross insects on St. Croix, U.S. Virgin Islands, to suppress the tobacco budworm (Lepidoptera: Noctuidae); infusion of sterility into a native population. J. Econ. Entomol. 76: 1353-1359.

Proshold, F. I. \& L. E. LaChance. 1974. Analysis of sterility in hybrids from interspecific crosses between Heliothis virescens and H. subflexa. Ann. Entomol. Soc. Am. 67: 445-449.

Proshold, F. I., L. E. LaChance \& R. D. Richard. 1975. Sperm production and transfer by Heliothis virescens, $H$. subflexa, and sterile hybrid males. Ann. Entomol. Soc. Am. 68: 31-34.

Proshold, F. I., D. F. Martin, M. L. Laster, J. R. Raulston \& A. N. Sparks. 1983a. Release of backcross insects on St. Croix to suppress the tobacco budworm (Lepidoptera: Noctuidae): methodology and dispersal of backcross insects. J. Econ. Entomol. 76: 885-891.

Proshold, F. I., J. R. Raulston, D. F. Martin \& M. L. Laster. 1983b. Release of backcross insects on St. Croix to suppress the tobacco budworm (Lepidoptera: Noctuidae): behavior and interaction with native insects. J. Econ. Entomol. 76: 626-631.

Richard, R. D., L. E. LaChance \& F. I. Proshold. 1975. An ultrastructural study of sperm in sterile hybrids from crosses of Heliothis virescens and Heliothis subflexa. J. Econ. Entomol. 8: 35-39.

Received for publication 23 March 1987; accepted 23 October 1987. 